\title{
Sagittal Lumbar Alignment Following Axial Lumbar Interbody Fusion with TranS1
}

Nitin Kukkar ${ }^{1}$, CPT Matthew C Mai ${ }^{1}$, Ashim Gupta ${ }^{1,2}$, Devraj Banerjee ${ }^{1}$, Neru Bedi ${ }^{1}$, Benjamin J Main ${ }^{2,3}$ and Per Freitag ${ }^{1 *}$

${ }^{1}$ Division of Orthopaedics and Rehabilitation, Department of Internal Medicine, Southern Illinois University School of Medicine, Springfield, IL, USA ${ }^{2}$ Department of Medical Microbiology, Immunology \& Cell Biology, Southern Illinois University, School of Medicine, Springfield, IL, USA

${ }^{3}$ University of Illinois at Springfield, Springfield, IL, USA

\author{
Abstract \\ Design: Retrospective study. \\ Objective: To examine and compare pre/postoperative sagittal alignment of the lumbar spine following AxiaLIF ${ }^{\circledR}$ \\ and to identify patient category with respect to preservation/restoration of lumbar lordosis.
}

Background: Interbody arthrodesis is an effective treatment for lower back pain and provides immediate structural support with high fusion rates. AxiaLIF ${ }^{\circledR}$ is an interbody device to be implanted through a paracoccygeal approach. Sagittal alignment change after AxiaLIF ${ }^{\circledR}$ has not been studied in past literature.

Methods: Retrospective study of all patients who underwent a $360^{\circ}$ lumbar interbody fusion at L5-S1 and L4-S1 with AxiaLIF ${ }^{\circledR}$ between Nov. 2008 and Sept. 2009. Surgeries were performed with patients prone on a Jackson table. Lumbar Cobb angles were measured at L1-S1, L4-S1 and individual lumbar levels. The sacral slope and percentage of total lordosis coming from the L4-S1 levels were also recorded.

Results: 60 patients identified for inclusion (mean age: 44 years). No difference in total average lordosis was observed preoperatively $\left(47.9^{\circ}\right)$ versus postoperatively $\left(47.7^{\circ}\right)$. The difference between pre and postoperative Cobb angles at the L4-S1 and L4-L5 levels was statistically significant ( $p=0.022$ and 0.029 , respectively). The change in percentage of total lordosis coming from L4-S1 segments (68.9\% preoperatively vs. $56.5 \%$ postoperatively) was also significantly different $(p=0.0004)$. A $>10^{\circ}$ postoperative change in total lordosis, L4-S1, and SS occurred in $18 \%, 20 \%$, and $11 \%$ respectively. $50 \%$ and $43 \%$ of patients had a $>5^{\circ}$ change at the individual segments of L4-L5 and L5-S1.

Conclusions: A significant portion single and multilevel fusions with AxiaLIF $^{\circledR}$ had a statistically significant change at the L4-5 and L4-S1 levels. The percentage of total lordosis from the L4-S1 level decreased significantly in the multilevel group. Further observation will determine if change in alignment will impact outcomes or accelerate adjacent level disease.

Keywords: Sagittal alignment; Lumber interbody fusion; Lumbar lordosis; Presacral approach; AxiaLIF ${ }^{\circledR}$

Abbreviations: LBP: Lower Back Pain; AxiaLIF ${ }^{\circledR}$ : Axial Lumbar Interbody Fusion

\section{Introduction}

Back pain is a common problem and occurs in both young adults and older people. Cause of back pain can be varied and range from degenerative disk disease to lumbar canal stenosis. Lumbar fusion is a well-accepted treatment for recalcitrant low back pain (LBP) of mechanical origin with neural compromise not responding to conservative management. In the last decade, there has been a dramatic increase in the number of lumbar fusions performed. In 2001, the Swedish Lumbar Spine Study Group demonstrated in a prospective randomized study that lumbar fusion is superior to conservative treatment for disabling low back pain; however, there are currently no randomized studies demonstrating that any one technique is more efficacious than another [1,2]. Nevertheless, interbody arthrodesis using autografts, allografts, or cages in combination with segmental pedicle screw instrumentation is an effective treatment for lower back pain and provides immediate structural support along with high fusion rates [3]. The lowermost two levels of lumbar spine, i.e. L4 and L5, contribute most to the motion as well as normal lordosis of lumbar spine and also most commonly degenerate at times leading to recalcitrant back pain and radicular pain [4]. Axial lumbar interbody fusion (AxiaLIF $\left.{ }^{\circledR}\right)$ has been developed as a minimally invasive option for decompression and fusion at these two levels of lumbar spine (i.e. L5-S1 and L4-L5). AxiaLIF $^{\circledR}$ ((TranS1, Inc., Wilmington, NC) is an interbody device to be implanted through a para coccygeal approach. This device is fairly new and has been approved by FDA in 2004 for L5- S1 and in May 2008 for L4-S1 fusion to be used only with conjunction with a posterior fixation device such as pedicle screws or facet screws.

Historically, every new instrumentation system has generated tremendous enthusiasm. The same was the case with Harrington instrumentation. But long term studies revealed the drawbacks of this distraction instrumentation especially in lumbar spine. In 1973, Doherty [5] described a symptomatic fixed forward inclination of the trunk due to loss of normal lumbar lordosis following posterior spinal fusion for scoliosis with Harrington instrumentation. Shortly thereafter, Moe and Denis [6] coined the term "flatback syndrome" and reported their early results after treatment of that syndrome with vertebral extension osteotomies. Since then, flatback syndrome, which is also commonly known as fixed sagittal imbalance, has become a well-recognized entity. Farcy and Schwab $[7,8]$ described a subgroup of similar patients who

*Corresponding author: Per Freitag, Southern Illinois University, School of Medicine, Division of Orthopedics and Rehabilitation, P.O. Box 19679 Springfield, IL 62794-9679, USA, Tel: (217) 545-8865; Fax: (217) 545-7901; E-mail: agupta@siumed.edu

Received September 19, 2013; Accepted October 21, 2013; Published October 24,2013

Citation: Kukkar N, Mai CPTMC, Gupta A, Banerjee D, Bedi N, et al. (2013) Sagittal Lumbar Alignment Following Axial Lumbar Interbody Fusion with TranS1. J Spine 2: 143. doi:10.4172/2165-7939.1000143

Copyright: (C) 2013 Kukkar N, et al. This is an open-access article distributed under the terms of the Creative Commons Attribution License, which permits unrestricted use, distribution, and reproduction in any medium, provided the original author and source are credited. 
had what they termed "kyphotic decompensation syndrome" and "flat buttock syndrome," a fixed positive sagittal imbalance due to malalignment at the site of a spinal fusion to the sacrum performed with distraction instrumentation for etiologies other than scoliosis. Thus history has led to increasing recognition of the importance of sagittal balance and many studies have reported on sagittal spinal balance in asymptomatic individuals and low back pain patients in an attempt to predict the ideal lateral spinal curvatures in asymptomatic individual [4,9-18]. There is a wide range of normal lumbar lordosis between $30^{\circ}$ to $80^{\circ}$ with the average begin about 60 degrees with L4-S1 providing nearly $2 / 3$ of total lordosis $[4,18]$. Furthermore, optimal sagittal balance obtained with surgical correction of the spinal deformity also affects the environment for bony union and preservation of the adjacent levels $[14,15,19,20]$. Therefore, restoration of normal spinal sagittal balance should be a primary goal of any reconstructive spine surgery.

AxiaLIF $^{\circledR}$ is distraction instrumentation and relies on indirect decompression of nerve roots and cauda equina. To the best of our knowledge, this relatively new minimally invasive device has not been evaluated for the change in sagittal balance in the past literature. Thus given the importance of sagittal alignment, the purpose of this study was to examine the change in sagittal alignment of the lumbar spine following use of this procedure and to identify the patient population with maximum change in terms of preoperative Cobb values. We hypothesize that Axial IF will restore the sagittal alignment of lumbar spine or will increase the lumbar lordosis in all group of patients.

\section{Materials and Methods}

All patients who underwent a 360 degree lumbar interbody fusion at L5-S1 and L4-S1 with AxiaLIF ${ }^{\circledR}$ between Nov. 2008 and Sept. 2009 were identified. Data were collected as part of a project given an IRB exemption determination. The inclusion criterions are demonstrated as follows: patients experiencing degenerative disk disease L4-5, L5-S1, spondylolisthesis Grade 1, or EMG suggestive of L4/5/S1 radiculopathy. The exclusion criterions are demonstrated as follows: patients experiencing spondylolisthesis grade 3 and 4, scoliosis, transitional vertebra, previous spine surgery, or multilevel lumbar spondylosis. The diagnosis for operation was established using clinical, plain, and dynamic roentgenographic, myelographic, computed tomography (CT) and magnetic resonance imaging techniques.

The surgical procedure involved placing the patient on the Jackson table in the prone position with support under the chest and pelvis with minimal flexion of the hips to allow normal lordosis of the lumbar spine (Figure 1). Two C-arms were positioned for simultaneous visualization of the AP and lateral views of the lumbar spine, sacrum, and coccyx. A $2 \mathrm{~cm}$ incision next to the coccyx was made, the deep fascia was opened, and a pathway was made to the anterior sacrum pushing the rectum anteriorly from the mesorectal soft tissue plane.

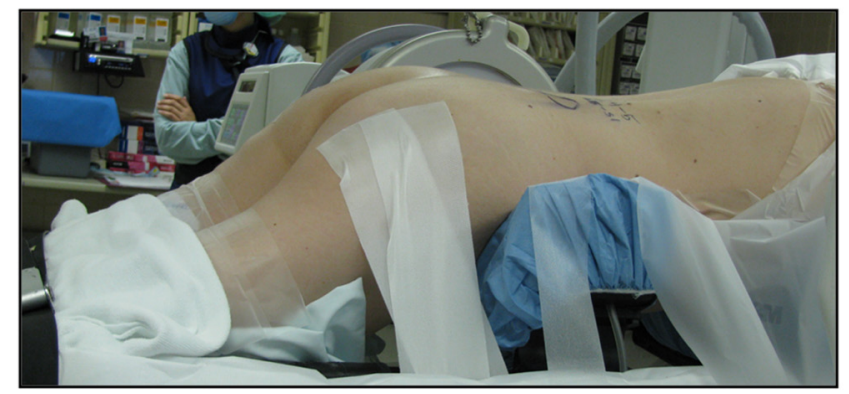

Figure 1: Intraoperative positioning for access to the presacral space.
The sacral promontory was entered, dilated, the disc material was excised, and crushed cancellous allograft bone graft mixed with iliac crest bone marrow aspirate was placed. The implant screw was then placed achieving distraction based on the amount of disc collapse prior to surgery. Posterior percutaneous instrumentation was then placed. The wounds were closed in layers with absorbable suture.

A standard set of $\mathrm{x}$-rays were done before and after surgery at 3 month follow up with a standard protocol. All radiographs were taken with the patient standing and the fists resting on the ipsilateral clavicles. Angulations were measured with digital radiographs on computer. The mean values of all measurements, as well as the standard deviations were then computed. Spondylolisthesis was assessed by each investigator using the Meyerding methodology [21,22]. Total and segmental angulation was determined using the Cobb technique, with total angulation measured between the superior endplate of L1 and the superior endplate of S1 [23]. The L4-S1 angulation was also measured pre- and postoperatively and the total amount of lordosis occurring from L4-S1 was calculated as a percentage of L1-S1. The sacral slope was used to measure pelvic orientation as described by Legaye et al. with the angle between the horizontal reference line and the superior endplate of S1 [24]. Segmental kyphosis was calculated using the Cobb technique. Each patient was sub classified by lordosis type using an abbreviated version of the technique described by Roussouly et al. [18] in view of the fact that long lateral thoraco-lumbar radiographs were not available for any of the patients. For the purpose of our analysis we divided the group into Type $1, \mathrm{SS}<35^{\circ} \&$ apex of lordosis in the center of L5 vertebral body; Type 2, SS $<35^{\circ} \&$ apex of lordosis at the base of the L4 vertebral body; Type $3, \mathrm{SS}$ is between $35^{\circ}$ and $45^{\circ} \&$ the apex of lordosis in the center of the L4 vertebral body, Type 4, SS $>45^{\circ}$ \& the apex of lordosis in the base of the L3 vertebral body or higher.

\section{Statistical analysis}

Descriptive statistics were performed on all data elements. Data were reported as the mean \pm standard deviation or in percentages. Independent Student's t-tests were used to compare means between subgroups. Statistical significance was set at a p-value $<0.05$. Data were analyzed using Graph Pad Prism version 4.03 (Graph Pad Software, Inc., San Diego, CA USA).

\section{Results}

Sixty patients were identified (average age of 47 years); 32 underwent a single level fusion (L5-S1) and 28 had a multilevel fusion (L4-S1) by a single experienced senior spine surgeon (P.F.). For the multilevel fusion, 26 patients received bilateral posterior percutaneous pedicle screw and rod (Medtronic Sextant) fixation; 24 at L4 and S1 and 2 with screws placed at L4, L5, and S1 (Figure 2). Six patients received percutaneous facet screw fixation. For the single level fusion, 14 patients received posterior percutaneous pedicle screw and rod (Medtronic Sextant) fixation at L5 and S1and 14 received percutaneous facet screw fixation (Figure 3). Thirteen patients did not have complete pre or postoperative standing radiographs and were excluded from analysis.

\section{Multilevel fusion}

The results for sacral slope, Cobb angles for total lordosis (L1S1), L4-S1 and individual lumbar segments are shown in Table 1. The average total lordosis did not change $\left(47.9^{\circ}\right.$ to $\left.47.7^{\circ}\right)$ and there were no statistically significant changes at L1-L2, L2-L3, L3-L4 or L5-S1. There were statistically significant changes in the segmental Cobb angles at L4-S1 ( $p=0.022)$ and L4-L5 ( $p=0.029)$. The percentage of lordosis occurring at the bottom two segments also decreased significantly from $68.9 \%$ to $56.5 \%(p=0.0004)$. 


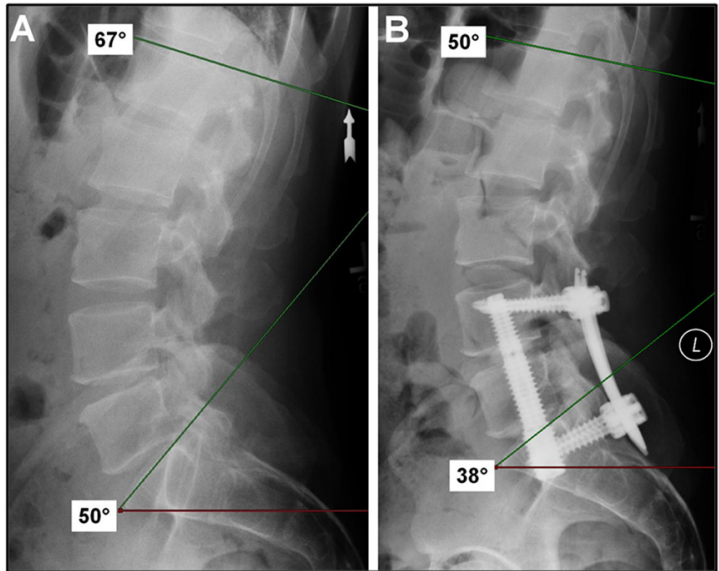

Figure 2: Pre-(A) and post-operative (B) standing lateral radiographs following two-level AxiaLIF with posterior percutaneous pedicle screw instrumentation. This case represents a decrease in lumbar lordosis of $17^{\circ}$ and a decrease in the sacral slope of $12^{\circ}$.

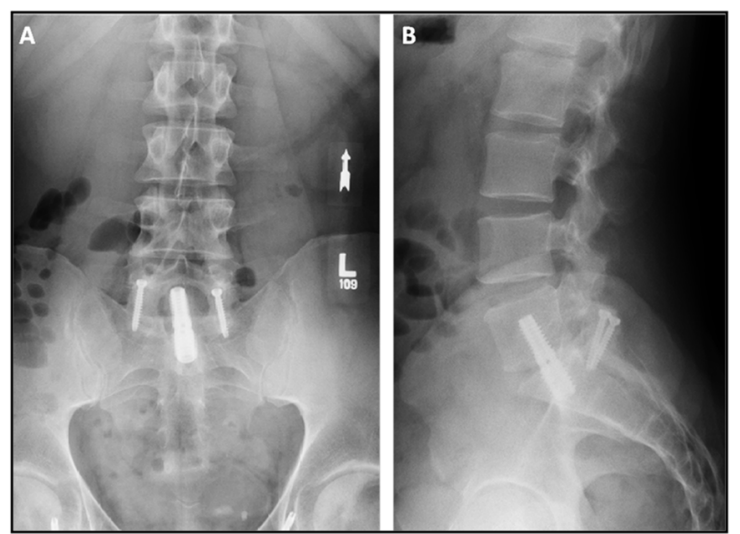

Figure 3: Post-operative AP (A) and Lateral $(B)$ radiographs following single level AxiaLIF with facet screws.

\begin{tabular}{|c|c|c|c|}
\hline & L4-S1 pre $\left(^{\circ}\right)$ & L4-S1 post $\left(^{\circ}\right)$ & P-value \\
\hline L1-S1 & $47.9 \pm 12.0$ & $47.7 \pm 11.0$ & 0.944 \\
\hline L4-S1 & $32.9 \pm 9.7$ & $27.3 \pm 8.3$ & 0.022 \\
\hline L1-L2 & $3.9 \pm 2.6$ & $4.7 \pm 3.0$ & 0.299 \\
\hline L2-L3 & $7.5 \pm 4.2$ & $9.6 \pm 3.8$ & 0.062 \\
\hline L3-L4 & $12.6 \pm 5.8$ & $13.6 \pm 5.3$ & 0.531 \\
\hline L4-L5 & $20.8 \pm 7.6$ & $16.1 \pm 8.0$ & 0.029 \\
\hline L5-S1 & $20.4 \pm 6.7$ & $18.9 \pm 5.7$ & 0.347 \\
\hline SS & $35.5 \pm 8.8$ & $36.0 \pm 8.6$ & 0.828 \\
\hline \%L L4-S1 & $68.9 \% \pm 13.6 \%$ & $56.5 \% \pm 10.9 \%$ & 0.0004 \\
\hline
\end{tabular}

Table 1: Lordosis, sacral slope, and \% Lordosis from L4-S1 for multilevel fusion.

Patients were then sub classified by lordosis type and those with a $\geq 5^{\circ}$ change at individual segments and $\geq 10^{\circ}$ change of total lordosis, lordosis at L4-S1 and sacral slope were determined (Tables 2 and 3). Patients with type 3 lumbar lordosis were relatively protected from changes in alignment with no patients having a $10^{\circ}$ or greater change in their total lordosis and only $10 \%$ having a change at L4-S1 and in the sacral slope. They were also more likely to not have changes at individual lumbar segments. Patients who were hyperlordotic pre-operatively; lordosis type 4 ; were more likely to have a decrease in total lordosis, lordosis from L4-S1, sacral slope, and at individual lumbar segments.
In particular, hyperlordotic spines were likely to have a decrease at the L4-L5 segment where $83 \%$ had a decrease. Hypolordotic patients, lordosis types 1 and 2 were more likely to have Cobb angle changes; either a decrease or an increase; than well-balanced spines, but less likely than hyperlordotic patients. In general sacral slope was relatively well preserved and a significant number of patients had a change in the Cobb angle at L4-L5.

\section{Single level fusion}

There were no statistically significant changes for sacral slope, Cobb angles for total lordosis (L1-S1), L4-S1 or individual lumbar segments in the single level fusion (Table 4). Sacral slope was well-preserved and actually increased. Approximately $2 / 3$ of the total lordosis occurred at the bottom two segments.

The results after sub classifying by lordosis type and analyzing those with $\mathrm{a} \geq 5^{\circ}$ change at individual segments and $\geq 10^{\circ}$ change of total lordosis, lordosis at L4-S1 and sacral slope are shown in Table 5 and 6. Lordosis type 3 spines were less likely to have larger changes in lordosis. Hypolordotic patients (lordosis type 2) were less likely to have significant Cobb angle changes at any segment. Hyperlordotic patients were very likely to have a measureable Cobb angle change at L5-S1 (71\%), L4-5 (71\%) and sacral slope (57\%).

\begin{tabular}{|c|c|c|c|c|}
\hline Lordosis Type & $\mathbf{n}$ & $\mathbf{\Delta L 1 - S 1}$ & $\boldsymbol{\Delta L 4 - S 1}$ & $\boldsymbol{\Delta} \mathbf{S S}$ \\
\hline 1 & 5 & $20 \%$ & $20 \%$ & $20 \%$ \\
\hline 2 & 6 & $33 \%$ & $33 \%$ & $0 \%$ \\
\hline 3 & 10 & $0 \%$ & $10 \%$ & $10 \%$ \\
\hline 4 & 6 & $33 \%$ & $50 \%$ & $17 \%$ \\
\hline
\end{tabular}

Table 2: Cobb angle change $\geq 10^{\circ}$ by Lordosis type for multilevel fusion.

\begin{tabular}{|c|c|c|c|c|c|c|}
\hline Lordosis Type & $\mathbf{n}$ & $\mathbf{\Delta L 1 - 2}$ & $\mathbf{\Delta L 2 - 3}$ & $\mathbf{\Delta L 3 - 4}$ & $\mathbf{\Delta L 4 - 5}$ & $\mathbf{\Delta L 5 - S 1}$ \\
\hline 1 & 5 & $20 \%$ & $20 \%$ & $0 \%$ & $40 \%$ & $80 \%$ \\
\hline 2 & 6 & $17 \%$ & $33 \%$ & $50 \%$ & $50 \%$ & $17 \%$ \\
\hline 3 & 10 & $30 \%$ & $20 \%$ & $20 \%$ & $40 \%$ & $30 \%$ \\
\hline 4 & 6 & $0 \%$ & $33 \%$ & $0 \%$ & $83 \%$ & $50 \%$ \\
\hline
\end{tabular}

Table 3: Cobb angle change $\geq 5^{\circ}$ by Lordosis type for multilevel fusion.

\begin{tabular}{|c|c|c|c|}
\hline & L5-S1 pre $\left.\mathbf{(}^{\circ}\right)$ & L5-S1 post $\left.\mathbf{(}^{\circ}\right)$ & P-value \\
\hline L1-S1 & $54.1 \pm 13.4$ & $57.3 \pm 13.3$ & 0.431 \\
\hline L4-S1 & $34.7 \pm 10.1$ & $36.7 \pm 12.9$ & 0.462 \\
\hline L1-L2 & $7.0 \pm 3.7$ & $6.9 \pm 3.0$ & 0.856 \\
\hline L2-L3 & $8.5 \pm 4.2$ & $10.6 \pm 5.4$ & 0.285 \\
\hline L3-L4 & $13.2 \pm 6.0$ & $15.8 \pm 5.8$ & 0.177 \\
\hline L4-L5 & $23.1 \pm 7.4$ & $19.9 \pm 6.7$ & 0.426 \\
\hline L5-S1 & $22.1 \pm 9.5$ & $20.9 \pm 7.4$ & 0.62 \\
\hline SS & $40.0 \pm 9.3$ & $42.5 \pm 11.3$ & 0.323 \\
\hline \%L L4-S1 & $65.0 \% \pm 14.9 \%$ & $65.2 \% \pm 25.6 \%$ & 0.78 \\
\hline
\end{tabular}

Table 4: Lordosis, sacral slope, and Lordosis from L4-S1 for single level fusion.

\begin{tabular}{|c|c|c|c|c|}
\hline Lordosis Type & $\mathbf{n}$ & $\mathbf{\Delta L 1 - S 1}$ & $\mathbf{\Delta L 4 - S 1}$ & $\boldsymbol{\Delta S S}$ \\
\hline 2 & 6 & $33 \%$ & $0 \%$ & $17 \%$ \\
\hline 3 & 7 & $29 \%$ & $29 \%$ & $29 \%$ \\
\hline 4 & 7 & $43 \%$ & $29 \%$ & $57 \%$ \\
\hline
\end{tabular}

Table 5: Cobb angle change $\geq 10^{\circ}$ by Lordosis type for single level fusion.

\begin{tabular}{|c|c|c|c|c|c|c|}
\hline Lordosis Type & $\mathbf{n}$ & $\mathbf{\Delta L 1 - 2}$ & $\mathbf{\Delta L 2 - 3}$ & $\mathbf{\Delta L 3 - 4}$ & $\mathbf{\Delta L 4 - 5}$ & $\mathbf{\Delta L 5 - S 1}$ \\
\hline 2 & 6 & $17 \%$ & $17 \%$ & $17 \%$ & $33 \%$ & $0 \%$ \\
\hline 3 & 7 & $14 \%$ & $29 \%$ & $29 \%$ & $43 \%$ & $86 \%$ \\
\hline 4 & 7 & $0 \%$ & $43 \%$ & $29 \%$ & $71 \%$ & $71 \%$ \\
\hline
\end{tabular}

Table 6: Cobb angle change $\geq 5^{\circ}$ by Lordosis type for single level fusion. 


\section{Discussion}

The present retrospective study investigated the sagittal alignment after AxiaLIF ${ }^{\circledR}$ L4-S1 and L5-S1 fusion. AxiaLIF ${ }^{\circledR}$ is implanted through presacral approach after diskectomy and the screw increases the disk height by distraction. The implant is used in conjunction with posterior fixation. In our series, all patients first underwent discectomy and AxiaLIF $^{\circledR}$ insertion followed by posterior instrumentation. The results of our study show that there are small decreases in lordosis in the lower lumbar segments. The change was mostly seen in the hyperlordotic group of patients. Nevertheless sacral slope was maintained. Interestingly, we found that patients undergoing a 2 level fusion had a lower sacral slope $\left(35.5^{\circ}\right)$ than patients undergoing a single level fusion $\left(40.0^{\circ}\right)$. Roussouly noted that patients with low sacral slope (Roussouly type 1 and 2) were more prone to disc hernations [18]. The majority of our patients received fusion for degenerative disc disease without significant stenosis. Patients with multilevel symptomatic disc herniations and degeneration had a lower sacral slope which is consistent with Roussoully's observations in these patients. We had a higher percentage of hyperlordotic patients (lordosis type 4) having only single level disease than multilevel disease, $35 \%$ vs. $22 \%$.

Previous work has reported a correlation between poor clinical outcome and positive sagittal balance [25]. Patients with suboptimal sagittal balance had significantly lower total and self-image subscale Scoliosis Research Society (SRS)-24 outcome scores compared with patients with optimal balance in long fusions in adult patients [26]. Same authors determined the factors controlling optimal sagittal balance after long adult lumbar instrumentation and proposed a Cobb angle difference of $>20^{\circ}$ between lumbar lordosis and thoracic kyphosis (higher lordosis) [26]. However, 3.7 years after surgery, an increase of thoracic kyphosis at an average $14^{\circ}$ was observed [26]. However, although the relationship between LBP and T12-S1 lumbar lordosis is not yet completely documented with evidence-based data, the importance of postoperative loss of physiologic sagittal plane curvatures has been well shown, particularly with reference to postsurgical flat back syndromes and posttraumatic kyphosis $[9,15,19,27,28]$. On the contrary, in a recent study, Korovessis et al. concluded that neither thoracic kyphosis, nor lumbar lordosis or sagittal C7-plumbline was shown to affect LBP. They believed that, at least theoretically, Cobb measurements merely represent the relative inclination between upper endplate of T12 and upper endplate of S1, whereas the deviation of the apical lumbar vertebra from C7-plumbline represents the real sagittal alignment of this spinal segment and this deviation along with fusion rates significantly affect LBP after surgery [29].

Prior studies showed an association between loss of lumbar lordosis, degenerative changes in the spine, and development of symptomatic LBP [25,30-34]. However, it should be mentioned that decreases in normal lumbar lordosis of up to $20^{\circ}$ have been recognized as a consequence of aging and degeneration [35]. Although a lumbar fusion may be successful in alleviating back pain and achieving stabilization of the fused segments, fixed lumbar motion segments after instrumentation may increase stress on unfused spinal segments and cause accelerate degeneration of the adjacent unfused segments [36,37].

Although lumbar lordosis is mostly located in the L4-S1 spinal area, surgical positioning is critical to maintaining lumbar lordosis and preventing flat back syndrome after spinal fusion [4]. If the patient is positioned in a manner that decreases lumbar lordosis or kyphosis, it may be difficult or even impossible to restore lordosis adequately through rod contouring or implant manipulation intra-operatively [38-41]. Although the normal physiological lumbar lordosis has been investigated by several authors, the ideal intraoperative position for spinal fusion is unknown $[42,43]$. Several reports state that the greater the increase in the angle of intraoperative hip flexion, the lesser the intraoperative total lumbar lordosis and segmental lordosis and if sagittal balance is to be maintained postoperatively after spinal instrumentation and fusion, physiological lordosis must be obtained by intraoperative positioning $[40,41,44]$. Part of the technique for insertion of AxiaLIF ${ }^{\circledR}$ is to have access to presacral space which is easier with hips flexed to allow for working area for instruments. Special attention was paid by the authors of this study on appropriately positioning of the patients and supporting the iliac crests and not the upper thighs in order to maintain lordosis. We found the Jackson table to be effective in maintaining intraoperative physiological lordosis as shown by previous studies, and we positioned patients with the hips only slightly flexed to achieve access as well as to maintain lordosis [45].

Jagannathan et al. investigated the effect of TLIF on sagittal balance [46]. The result showed that TLIF can restore the sagittal alignment in lumbar spine. But in comparison to our study, the surgical procedure was performed at all the levels of lumbar spine, removal of a part of posterior elements was a part of the procedure and the patient had poor sagittal balance preoperatively with 99 levels having spondylolisthesis. Reduction in spondylolisthesis can result in restoration of balance. In our series, the patients presented with DDD and grade 1 listhesis. Also the surgery was performed at lowermost lumbar levels and posterior elements were preserved with percutaneous instrumentation and preservation of posterior lumbar musculature. Overall standing lumbar alignment (L1-S1 Cobb's angle) and sacral slope was maintained. The significance of focal loss of lumbar lordosis in hyperlordotic patients in view of these findings is yet to be determined.

Hsieh et al. compared ALIF with TLIF and concluded that ALIF is better than TLIF in maintaining the sagittal balance [47]. According to them, the ability of ALIF to put the graft anterior to the sagittal axis contributes to restoration of sagittal balance whereas TLIF is limited in the capability to place the graft sufficiently anterior to IAR to allow substantial introduction of lordosis [47]. AxiaLIF ${ }^{\circledR}$ relies on distraction of vertebral bodies anteriorly and in a way is comparable to ALIF in terms of theoretical distraction anterior to IAR. The difference is that it relies on indirect distraction.

Nevertheless, we think that the small loss of lumbar lordosis at the lowermost two levels is due to the fact that AxiaLIF ${ }^{\circledR}$ is a straight implant and relies on overall distraction of lumbar interbody space and does not differentially distract anterior from posterior vertebral body. The second reason can be the fact that this is a minimally invasive approach and the facet joints are preserved, so there is only limited possibility of compression of facet joints posteriorly to alter and gain lordosis. The clinical significance of these findings is yet to be determined. Further prospective studies are needed to assess how the change in sagittal balance and implantation of a rigid straight implant affects the clinical outcomes. This is especially important taking into consideration that AxiaLIF $^{\circledR}$ insertion and posterior percutaneous implants preserve proximal facet joints and can prevent degeneration at the proximal fused levels. Another consideration is to put posterior pedicle screw instrumentation first to achieve compression at posterior facet joints and to achieve lordosis. This change in technique can help even more in Roussouly type 1 and 2.

Our study is not without limitations. First of all, it is a retrospective study and relies on smaller cohort of patients. Secondly the post operative radiographs used in the study were done at fairly short follow up of 3 months. Thirdly the study focuses on lumbar sagittal alignment 
and the uses an abbreviated Roussouly classification to present trends in alignment changes following surgery. Fourthly our study is underpowered to demonstrate a statistically significant difference between the subgroups. However, we still think that this study can help in choosing the correct treatment options for a selected subset of patients and would serve as a basis for future studies on evaluating long term effect of small change in lumbar alignment on the overall clinical results and adjacent segment degeneration.

\section{Conclusions}

A significant portion of both single and multilevel fusions with AxiaLIF $^{\circledR}$ had a small change in their lordosis and sacral slope. Statistically significant changes were at the L4-5 and L4-S1 level in the multilevel group with reciprocal, but not significant changes at the lumbar segments superior. The percentage of total lordosis from the L4S1 level decreased significantly in the multilevel group. Lordosis type 3 was relatively protected from change in lordosis. Continued follow up of these patients will tell whether the change in sagittal alignment will lead to continued pain or accelerated adjacent segment disease. Lordosis type may help determine patients at risk for a change in sagittal alignment. Small increases or decreases in alignment may be beneficial in some patients. Careful intra-operative positioning is paramount to recreating the patient's lordosis. Future work with changing the order of the procedure is under way.

\section{Ethics}

Data were collected as part of a project given an IRB exemption determination.

The views expressed in this article are those of the author and do not necessarily reflect the official policy or position of the Air Force, the Department of Defense or the U.S. Government.

\section{References}

1. Fritzell P, Hagg O, Wessberg P, Nordwall A (2001) 2001 Volvo Award Winner in Clinical Studies: Lumbar fusion versus nonsurgical treatment for chronic low back pain: a multicenter randomized controlled trial from the Swedish Lumbar Spine Study Group. Spine (Phila Pa 1976) 26: 2521-2532.

2. Fritzell $P$, Hägg $O$, Wessberg $P$, Nordwall $A$; Swedish Lumbar Spine Study Group (2002) Chronic low back pain and fusion: a comparison of three surgical techniques: a prospective multicenter randomized study from the Swedish lumbar spine study group. Spine (Phila Pa 1976) 27: 1131-1141.

3. Burkus JK, Schuler TC, Gornet MF, Zdeblick TA (2004) Anterior lumbar interbody fusion for the management of chronic lower back pain: current strategies and concepts. Orthop Clin North Am 35: 25-32.

4. Korovessis PG, Stamatakis MV, Baikousis AG (1998) Reciprocal angulation of vertebral bodies in the sagittal plane in an asymptomatic Greek population. Spine (Phila Pa 1976) 23: 700-704.

5. Doherty JH (1973) Complications of fusion in lumbar scoliosis. Proceedings of the Scoliosis Research Society. J Bone Joint Surg Am 55: 438.

6. Moe JH, Denis F (1977) The iatrogenic loss of lumbar lordosis. Orthop Trans 1: 131

7. Farcy JP, Schwab FJ (1997) Management of flatback and related kyphotic decompensation syndromes. Spine (Phila Pa 1976) 22: 2452-2457.

8. Farcy JP, Schwab F (2000) Posterior osteotomies with pedicle substraction for flat back and associated syndromes. Technique and results of a prospective study. Bull Hosp Jt Dis 59: 11-16.

9. Gödde S, Fritsch E, Dienst M, Kohn D (2003) Influence of cage geometry on sagittal alignment in instrumented posterior lumbar interbody fusion. Spine (Phila Pa 1976) 28: 1693-1699.

10. Goldstein JA, Macenski MJ, Griffith SL, McAfee PC (2001) Lumbar sagitta alignment after fusion with a threaded interbody cage. Spine (Phila Pa 1976) 26: $1137-1142$
11. Griffith SL, Shelokov AP, Buttner-Janz K, LeMaire JP, Zeegers WS (1994) A multicenter retrospective study of the clinical results of the LINK SB Charite intervertebral prosthesis. The initial European experience. Spine (Phila Pa 1976) 19: 1842-1849.

12. Hammerberg EM, Wood KB (2003) Sagittal profile of the elderly. J Spinal Disord Tech 16: 44-50.

13. Huang RC, Girardi FP, Cammisa Jr FP, Tropiano P, Marnay T (2003) Long-term flexion-extension range of motion of the prodisc total disc replacement. J Spinal Disord Tech 16: 435-440.

14. Korovessis P, Stamatakis M, Baikousis A (1999) Segmental roentgenographic analysis of vertebral inclination on sagittal plane in asymptomatic versus chronic low back pain patients. J Spinal Disord 12: 131-137.

15. Lazennec JY, Ramaré S, Arafati N, Laudet CG, Gorin M, et al. (2000) Sagittal alignment in lumbosacral fusion: relations between radiological parameters and pain. Eur Spine J 9: 47-55.

16. Vaz G, Roussouly P, Berthonnaud E, Dimnet J (2002) Sagittal morphology and equilibrium of pelvis and spine. Eur Spine J 11: 80-87.

17. Gelb DE, Lenke LG, Bridwell KH, Blanke K, McEnery KW (1995) An analysis of sagittal spinal alignment in 100 asymptomatic middle and older aged volunteers. Spine (Phila Pa 1976) 20: 1351-1358.

18. Roussouly P, Gollogly S, Berthonnaud E, Dimnet J (2005) Classification of the normal variation in the sagittal alignment of the human lumbar spine and pelvis in the standing position. Spine (Phila Pa 1976) 30: 346-353.

19. Kumar MN, Baklanov A, Chopin D (2001) Correlation between sagittal plane changes and adjacent segment degeneration following lumbar spine fusion. Eur Spine J 10: 314-319.

20. Umehara S, Zindrick MR, Patwardhan AG, Havey RM, Vrbos LA, et al. (2000) The biomechanical effect of postoperative hypolordosis in instrumented lumba fusion on instrumented and adjacent spinal segments. Spine (Phila Pa 1976) 25: $1617-1624$

21. Marchetti PG, Binazzi R, Briccoli A, Vaccari V, Borelli P, et al. (1994) The surgical treatment of spondylolisthesis. Chir Organi Mov 79: 85-91.

22. Meyerding HW (1956) Spondylolisthesis; surgical fusion of lumbosacral portion of spinal column and interarticular facets; use of autogenous bone grafts for relief of disabling backache. J Int Coll Surg 26: 566-591.

23. Morrissy RT, Goldsmith GS, Hall EC, Kehl D, Cowie GH (1990) Measurement of the Cobb angle on radiographs of patients who have scoliosis. Evaluation of intrinsic error. J Bone Joint Surg Am 72: 320-327.

24. Legaye J, Duval-Beaupère G, Hecquet J, Marty C (1998) Pelvic incidence: a fundamental pelvic parameter for three-dimensional regulation of spinal sagittal curves. Eur Spine J 7: 99-103.

25. La Grone MO (1988) Loss of lumbar lordosis. A complication of spinal fusion for scoliosis. Orthop Clin North Am 19: 383-393.

26. Kim YJ, Bridwell KH, Lenke LG, Rhim S, Cheh G (2006) An analysis of sagitta spinal alignment following long adult lumbar instrumentation and fusion to $L 5$ or S1: can we predict ideal lumbar lordosis? Spine (Phila Pa 1976) 31: 2343-2352.

27. Glassman SD, Farcy JC (1993) Late deformities. In: Thoracolumbar Spine Fractures. Floman, Y., Farcy, J-PC, Argenson, C, eds. New York, NY: Raven Press, Ltd.

28. Lagrone MO, Bradford DS, Moe JH, Lonstein JE, Winter RB, et al. (1988) Treatment of symptomatic flatback after spinal fusion. J Bone Joint Surg Am 70: $569-580$

29. Korovessis P, Repantis T, Papazisis Z, lliopoulos P (2010) Effect of sagittal spinal balance, levels of posterior instrumentation, and length of follow-up on low back pain in patients undergoing posterior decompression and instrumented fusion for degenerative lumbar spine disease: a multifactorial analysis. Spine (Phila Pa 1976) 35: 898-905.

30. Evcik D, Yücel A (2003) Lumbar lordosis in acute and chronic low back pain patients. Rheumatol Int 23: 163-165.

31. Jackson RP, Kanemura T, Kawakami N, Hales C (2000) Lumbopelvic lordosis and pelvic balance on repeated standing lateral radiographs of adult volunteers and untreated patients with constant low back pain. Spine (Phila Pa 1976) 25 575-586.

32. Jackson RP, McManus AC (1994) Radiographic analysis of sagittal plane 
alignment and balance in standing volunteers and patients with low back pain matched for age, sex, and size. A prospective controlled clinical study. Spine (Phila Pa 1976) 19: 1611-1618.

33. Kostuik JP, Maurais GR, Richardson WJ, Okajima Y (1988) Combined single stage anterior and posterior osteotomy for correction of iatrogenic lumbar kyphosis. Spine (Phila Pa 1976) 13: 257-266.

34. Noun Z, Lapresle P, Missenard G (2001) Posterior lumbar osteotomy for fla back in adults. J Spinal Disord 14: 311-316.

35. Bridwell KH, Betz R, Capelli AM, Huss G, Harvey C (1990) Sagittal plane analysis in idiopathic scoliosis patients treated with Cotrel-Dubousset instrumentation. Spine (Phila Pa 1976) 15: 644-649.

36. Chow DH, Luk KD, Evans JH, Leong JC (1996) Effects of short anterior lumbar interbody fusion on biomechanics of neighboring unfused segments. Spine (Phila Pa 1976) 21: 549-555.

37. Park P, Garton HJ, Gala VC, Hoff JT, McGillicuddy JE (2004) Adjacent segmen disease after lumbar or lumbosacral fusion: review of the literature. Spine (Phila Pa 1976) 29: 1938-1944.

38. Guanciale AF, Dinsay JM, Watkins RG (1996) Lumbar lordosis in spinal fusion A comparison of intraoperative results of patient positioning on two different operative table frame types. Spine (Phila Pa 1976) 21: 964-969.

39. Peterson MD, Nelson LM, McManus AC, Jackson RP (1995) The effect of operative position on lumbar lordosis. A radiographic study of patients under anesthesia in the prone and 90-90 positions. Spine (Phila Pa 1976) 20: 14191424

40. Benfanti PL, Geissele AE (1997) The effect of intraoperative hip position on maintenance of lumbar lordosis: a radiographic study of anesthetized patients and unanesthetized volunteers on the Wilson frame. Spine (Phila Pa 1976) 22 2299-2303.

41. Stephens GC, Yoo JU, Wilbur G (1996) Comparison of lumbar sagittal alignment produced by different operative positions. Spine (Phila Pa 1976) 21 1802-1806.

42. Bernhardt M, Bridwell KH (1989) Segmental analysis of the sagittal plane alignment of the normal thoracic and lumbar spines and thoracolumbar junction. Spine (Phila Pa 1976) 14: 717-721.

43. Stagnara P, De Mauroy JC, Dran G, Gonon GP, Costanzo G, et al. (1982) Reciprocal angulation of vertebral bodies in a sagittal plane: approach to references for the evaluation of kyphosis and lordosis. Spine (Phila Pa 1976) 7: $335-342$.

44. Tan SB, Kozak JA, Dickson JH, Nalty TJ (1994) Effect of operative position on sagittal alignment of the lumbar spine. Spine (Phila Pa 1976) 19: 314-318.

45. Harimaya K, Lenke LG, Mishiro T, Bridwell KH, Koester LA, et al. (2009) Increasing lumbar lordosis of adult spinal deformity patients via intraoperative prone positioning. Spine (Phila Pa 1976) 34: 2406-2412.

46. Jagannathan J, Sansur CA, Oskouian RJ Jr, Fu KM, Shaffrey CI (2009) Radiographic restoration of lumbar alignment after transforaminal lumbar interbody fusion. Neurosurgery 64: 955-963.

47. Hsieh PC, Koski TR, O'Shaughnessy BA, Sugrue P, Salehi S, et al. (2007) Anterior lumbar interbody fusion in comparison with transforaminal lumbar interbody fusion: implications for the restoration of foraminal height, local disc angle, lumbar lordosis, and sagittal balance. J Neurosurg Spine 7: 379-386. 